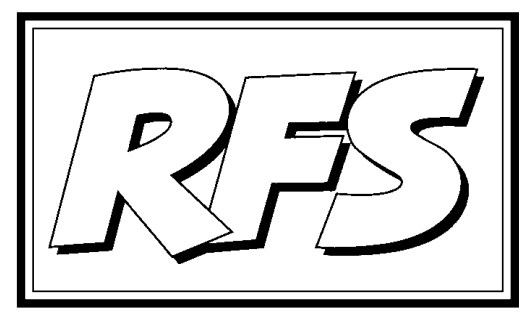

Revista de Fomento Social, 57 (2002), 151-173

\title{
El proceso de regionalización en Marruecos
}

\section{Raquel OJ EDA GARCÍA ${ }^{1}$}

\section{Introducción}

El objetivo principal de este artículo es analizar el proceso de regionalización iniciado en Marruecos. La palabra "proceso" tiene la intención de poner de manifiesto que la regionalización no es un fenómeno acabado y que lleva una larga andadura. La primera vez que se reconoce a la región como colectividad local (como las comunas y las prefecturas y provincias) es en la reforma constitucional de 1992. La siguiente reforma de la Constitución de 1996 ratifica esta decisión, pero el desarrollo normativo no se producirá hasta 1997.

Sin embargo, es necesario rescatar otro punto de inflexión en este proceso. Nos referimos a 1984, año en el que Hassan II, en uno de sus discursos dirigidos a los representantes locales de Fez, lanza la idea de una división regional para Marruecos con un marcado talante descentralizador.

1 Profesora de Ciencia Política y de la Administración. Universidad de Jaén. 
Para poder abordar el tema del proceso de regionalización, vamos a distinguir tres niveles de análisis: el político, el teórico-científico y el empírico. Entre estos tres niveles habrá momentos en los que sus contenidos coincidan y otros en los que se producirá un profundo distanciamiento. Tampoco se producirá una concantenación de hechos o existirá una relación directa entre ellos.

Por último, queríamos recordar que el concepto de descentralización utilizado en este proceso de Marruecos se asemeja más al que Francia ha tenido en cuenta para su proceso de descentralización iniciado con la llegada de Mitterrand al gobierno, que al concepto que ha articulado la construcción del estado de las autonomías y sus relaciones con los entes locales en España. En Marruecos la acepción de la descentralización estará más vinculada a la gestión administrativa que a la noción política de un mayor reconocimiento de autonomía a los entes locales.

En esta reflexión abordaremos el análisis empírico de la creación de las regiones como colectividad local, desde un enfoque neoinstitucional, cerrándolo con un breve balance de su corta historia.

Con el análisis de las fuentes secundarias que tratan esta cuestión, hemos podido comprobar que hay una serie de elementos que se repiten en casi todos los escritos y documentos. Reseñar estos elementos comunes nos permite, además, hacer una presentación general del tema de forma muy resumida ${ }^{2}$.

1. La distinción entre "regionalismo" y "regionalización" es una de las primeras tareas que con más exhaustividad se ha realizado desde el plano teórico.

2. La utilización de los términos "región", "planes de desarrollo" y "ordenación del territorio" están exentos en el discurso de cualquier connotación política. A estas palabras se las considera desde su perspectiva económica o administrativa. Una de las manifestaciones más claras está

2 En la Revue Marocaine d'Adminsitration locale et de développement podemos encontrar un amplio número de artículos y de publicaciones especiales dedicadas al tema de la regionalización. Otro elemento de trabajo es el documento publicado por el Secrétariat Général du Conseil National de la Jeunesse et de l'Avenir titulado Région, régionalisation et emploi. Cinquième session. Laâyoune, 15 et 16 janvier 1996. Entre los expertos más destacados podemos reseñar a M'hamed Zriouli y Mohamed Brahimi que tras pasar por puestos universitarios desempeñan en la actualidad altos cargos de la Administración. 
en el mismo principio que sirvió como guía a la hora de trazar la división regional. No se debía respetar las viejas identidades culturales, históricas o lingüísticas, bien al contrario, la integridad del territorio y la unidad nacional no deben ser puestos en cuestión.

3. El reconocimiento de la región como colectividad local por parte de los poderes públicos a través de las dos últimas reformas constitucionales (la de 1992 y la de 1996) no fue la consecuencia o el fruto de una demanda social o política sino que es hija de la voluntad unilateral del Monarca para reconocer la riqueza plural de su país, de dar una respuesta al Sahara y de estar al día de la situación económica mundial que se mueve en una tensión que pugna entre la globalización y la regionalización ${ }^{3}$.

4. El desnivel existente entre las propuestas políticas del Rey (en su discurso de 1984), las de los teóricos (entre 1984 y 1996) y la de la ley sobre la región de 1997. Desde nuestro punto de vista entendemos que el dahir ${ }^{4}$ de 2 de abril de 1997 no cumple con las expectativas creadas alrededor de estas propuestas por las siguientes razones: porque no se ha tocado el estatuto de la provincia; no se ha profundizado en la desconcentración; no es un sistema acabado ni en su sistema fiscal, ni competencial $y$, por supuesto, no se ha asumido la apuesta de una mayor democratización por la base.

5. Este fracaso, que tiene un primer avance en la misma redacción del dahir, ha sido justificado por el gobierno y por los antiguos partidos de la oposición (el Istiqlal y la USFP, actualmente en el gobierno desde 1997) aludiendo al carácter temporal de la reforma, a la crisis financiera que atravesaba el país en aquellos momentos y a la inmadurez política del pueblo e incluso de sus elites.

6. En estas fuentes secundarias también se puede comenzar a detectar una crítica. La construcción de la región como colectividad local, como

3 Brahimi, Mohamed, “La région au Maroc entre le virtuel et le réel". En Sedjari, Ali (dir.) (1996).

4 La definición literal de dahir es: decreto del Rey de Marruecos. El equivalente a una ley. En cuanto a las wilayas, otro término árabe que aparecerá en el texto hace referencia a otra colectividad local de reciente creación (en 1984) con el fin de reagrupar varias provincias con una cierta unidad urbanística, económica y humana. Con esta nueva colectividad local (aunque muy antigua en la tradición local magrebí) se pretende luchar contra la excesiva fragmentación del territorio en provincias y prefecturas y concentrar así, el poder en manos de la administración desconcentrada. 
un nivel más de la administración territorial, carece de efectos desde el punto de vista de la descentralización.

La debilidad de la construcción regional atraviesa todos sus estadios, desde el planteamiento teórico como descentralización administrativa, pasando por su desarrollo legislativo, hasta llegar a la institución. La región en la actualidad carece de recursos humanos, financieros y materiales y, lo que es más importante, es una institución carente del impulso político necesario para ser convertido en un verdadero ente descentralizado.

Ante este panorama cabe preguntarse, como hace Brahimi por qué la regionalización ha sido uno de los elementos claves del debate político ${ }^{5}$. Los partidos de la oposición que antes no se habían preocupado de la región ni de la descentralización se han sumado a esta ola de reformas institucionales que ha conocido Marruecos, imbuidas en su gran mayoría por el consenso, el diálogo y la concertación.

\section{La delimitación del concepto de regionalización}

La primera delimitación viene establecida por la distinción entre regionalización y regionalismo. Al respecto, Ben Osmane considera que "regionalización es un modo de organización territorial del Estado a partir de consideraciones socio-económicas, mientras que el regionalismo designa las doctrinas políticas fundadas sobre la afirmación de la existencia de comunidades culturales, sociológicas y económicas en el seno del Estado"6.

Para Abderrahim Fadil regionalización y regionalismo son dos conceptos indisociables. Una política de regionalización puede responder a las reivindicaciones que surgen de determinados grupos geográficos, especialmente si se trata de un país pluricultural. El regionalismo se manifiesta a través de las reivindicaciones de grupos locales dirigidas contra el poder central, e implican la defensa de una cultura y una lengua autóctona y el rechazo del modelo integracionista por ser entendido como un mecanismo de agresión política, económica y cultural.

5 Brahimi, Mohamed (1997), pp. 35-82.

6 Ben Osmane, Khalid toma estas definiciones del Lexique des termes politiques. Dalloz. Paris. 1974 y las cita textualmente en su artículo "La région: pourquoi et comment?". (1996) En Revue marocaine d'administration locale et développement. Série Thèmes actuels, no 8, pp. 101-105, p. 101. 
Existe el riesgo de confundir regionalización con descentralización. Esta confusión sólo es aceptable si consideramos al término "descentralización" como la designación del reparto de poderes entre el Estado y el escalón regional. Pero la identificación entre descentralización y regionalización no es exacta ya que el contenido de la regionalización, que depende en gran medida del contexto político, económico y social, es cambiante.

La descentralización se puede concebir como una división del trabajo administrativo en el que se permite a los interesados gestionarse sus asuntos de forma autónoma. La autonomía en la gestión implica el reconocimiento de la personalidad jurídica a las colectividades o a ciertas entidades y la elección de los órganos que van a gestionar los asuntos locales. Las primeras consecuencias que podemos deducir son las de una mayor democratización y la de una mayor independencia del poder central ${ }^{7}$.

Si profundizamos un poco más en el concepto de descentralización descubrimos que el mismo concepto tiene tres acepciones. La primera es la que resalta sólo la dimensión managerial. El concepto se ha limitado a la gestión, a la racionalización del reparto de competencias entre los diferentes niveles administrativos territoriales.

La segunda acepción resalta un aspecto más político de la descentralización entendida como un mecanismo capaz de guardar el equilibrio entre los poderes y las fuerzas políticas y única forma de evitar que el Estado Leviatán absorba a los individuos y a las instituciones. El equilibrio de poderes no se hace en función de los conceptos tradicionales de derecho constitucional entre el poder ejecutivo y el legislativo, sino entre distintas autoridades de sensibilidades políticas diferentes en todo el territorio nacional.

La tercera acepción subraya que lo que se persigue con la descentralización es la creación de un nuevo modo de definir el interés general. A partir de este momento, los actores nacionales no van a ser los únicos legitimados para realizar esta función, sino que también los actores locales en algunas materias pueden definir el interés general ${ }^{8}$.

Las políticas de regionalización pueden venir dictadas por los motivos más diversos. Puede ser fruto del intento de reducir el carácter excesivamente sectorial y centralizado del sistema de planificación económica y social.

7 Gruber, Annie (1996), p. 24

8 Blanc, Jacques y Remond, Bruno (1994), p. 18. 
Puede ser también promulgada con el fin de resolver las desigualdades y los desequilibrios originados por una política de desarrollo no equitativa. También puede tener como fin la modernización de las estructuras administrativas territoriales, o incluso reformar las instituciones constitucionales.

\section{El discurso del Rey Hassan II en la región del Centro Oeste (Fez, 1984)}

Analizamos, ahora, este discurso ya que en él los puntos principales de cómo el Monarca concibe la región. El modelo propuesto en Marruecos tenía como referente los Länder en Alemania, es decir, el establecimiento de unas regiones cuyas instituciones contaran con capacidad legislativa y con un sistema fiscal propio. El referente de las comunidades autónomas españolas también ha servido como posible modelo para el proceso de regionalización en Marruecos según los deseos de Hassan II.

Este discurso no ha dejado de sorprender a propios y a extraños. La similitud entre los deseos reflejados en el discurso y la realidad políticoinstitucional que luego provocaron es tan lejana que nos obliga a interrogarnos sobre el papel que jugó este discurso. Por otro lado, estas pretensiones tuvieron que ser justificadas y adaptadas a la realidad política, social y económica de Marruecos tanto por los expertos como por los políticos.

No es tan importante lo que en realidad se expresaba en el texto sino el valor de lo que se dijo, y los efectos que produjo. Estos dos aspectos que vamos a intentar poner de manifiesto están íntimamente unidos. El valor es incuestionable, forma parte de un discurso Real. A través de él, el Rey establece unos criterios generales que, en principio, deben ser desarrollados y puestos en práctica. Forman parte de los grandes objetivos de la política establecidos por el Monarca que decide hacerlos públicos.

Por tanto el valor de ese discurso no viene tanto por lo innovador, por lo que de ruptura significaba con el anterior mecanismo de regionalización, sino porque introduce en el debate político y en la opinión pública la cuestión de la región y de una de las formas más descentralizadas y democratizadoras que puedan conocer países cuya forma de Estado sea unitaria. Es más, pone como meta la estructura de un Estado de carácter federal.

La región que había sido un tema constantemente ignorado fue catapultado al candelero de los temas estrella en el debate político. Pero, al mismo tiempo, los expertos se vieron obligados a buscar la fórmula para, sin deslegitimar al Monarca, explicar que esa concepción de la región cuyo 
modelo eran los Länders alemanes no iba a ser aplicada en Marruecos.

¿Y los efectos? El principal efecto, no fue sólo el éxito de conseguir que se introdujera en el discurso político el tema de la región, sino que además fuera considerada de forma consensuada la necesidad de crear una nueva organización territorial que sirviera de nivel intermedio entre la provincia y el Estado, que supusiera un trampolín para un desarrollo económico más equilibrado y sostenido, y que permitiera una ordenación del territorio ajustada a las necesidades del Estado y del interés general.

Otra cuestión distinta sería la de plantearnos sobre los motivos que Ilevaron al Rey Hassan II a hacer unas manifestaciones de este tipo. Si no había demanda social ni cultural de una mayor descentralización regional como modo de garantizar una identidad y una gestión más autónoma de sus propios asuntos, y si desde ningún partido político la reivindicación de una profundización en la estructura regional era lanzada a la arena política, ¿qué llevo al Monarca a plantear el inicio de una política contraria a la llevada a cabo hasta aquellos momentos?

La razón también apuntada desde todas las perspectivas y con un alto grado de unanimidad es la de dar una respuesta al problema del Sahara o de las "provincias del sur recuperadas", como se les suele denominar, en el lenguaje oficial marroquí.

La proximidad de una posible celebración del referéndum para la autodeterminación del pueblo saharaui (tema aún hoy no resuelto), le llevó a proponer como solución para la integración del pueblo saharaui dentro del Estado marroquí, la construcción de una nueva región con el suficiente margen de maniobra para que, a pesar de formar parte de un estado unitario, tuviera la necesaria autonomía para poder decidir y aplicar aquellas normas que afectaran a sus competencias.

Como todo el mundo sabe, ni el referéndum se ha celebrado, ni la construcción de la nueva región ha supuesto la creación de una institución capaz de decidir y aplicar sus propias decisiones, dado el estrecho marco competencial y los escasos medios financieros y humanos de los que dispone.

Podríamos apuntar además otras dos posibles razones que justificarían que el Monarca hiciera una apuesta semejante. La primera es que el contexto internacional también estaba invadido por la misma preocupación. En Francia, las leyes sobre la descentralización se instauran a partir de 1982 con la 
llegada al poder del partido socialista. Deferre (que ocupaba la cartera de interior y de la descentralización) pone en marcha de forma rápida la maquinaria legislativa para impulsar un profundo cambio institucional, para iniciar un procedimiento de descentralización que ni siquiera hoy está acabado. A pesar de su reconocimiento jurídico-institucional en 1982, hasta 1986 las regiones no se pusieron en marcha, ya que hubo que esperar a la celebración de las elecciones para conformar a través del sufragio universal directo las asambleas regionales.

En España, es también la década de los ochenta cuando se va a completar el proceso de descentralización a través de la institucionalización de las transferencias competenciales a las recien creadas comunidades autónomas. En toda Europa, persiste el convencimiento de que una mayor descentralización en teoría facilita una mayor democratización y una participación más directa y real de los ciudadanos. El otro aspecto positivo que aporta la descentralización es que la creación de instituciones capaces de gestionar de forma autónoma no sólo en cuanto a la toma de decisiones se refiere, sino también al modo de financiación, mejora la calidad de la gestión y por tanto la prestación de los servicios. La descentralización se convirtió en uno de los puntos clave cada vez que se establecían los criterios para la reforma y la mejora dela administración. La modernización de la Administración pasaba por una mayor descentralización de sus centros de decisión, de la aplicación de sus políticas y de su financiación. De esta forma, estaba estrechamente ligada a los otros tres aspectos que eran también centrales en la reforma de la administración: mayor democratización y proximidad a los ciudadanos, mejora en la gestión y en la prestación de los servicios, y un cambio en la forma de reclutar y de salvar las rigideces de la función pública.

La segunda razón para explicar por qué el discurso de Fez en 1984 establece las bases de una realidad hasta aquella fecha impensada no es una razón exclusiva del proceso de regionalización puesto que ya se había dado ocho años antes para explicar otro proceso distinto. Se trata de la explicación que justifica la regionalización como una forma más de integrar las elites políticas y económicas dentro del juego institucional oficial semicontrolado.

Esta razón ya apuntada para explicar el importante avance en la descentralización instaurado con la carta comunal de septiembre de 1976, no carece de valor en el proceso de regionalización. El proyecto preveía la instauración 
de unas asambleas incluso con capacidad legislativa que gozarían no sólo de una capacidad de auto-gobierno en un plano político, sino incluso de financiación.

Para darle vida a esas asambleas y el impulso necesario a las instituciones regionales hacía falta políticos con una cierta vocación regional y altos funcionarios que ocupasen los puestos de nueva creación que son de una importancia vital para el éxito o el fracaso de la nueva región. La introducción en el juego político de un mayor número de actores no sólo debilita a los antiguos, sino que los controla a través de su integración en los mecanismos formales.

\section{Claves para analizar la situación actual de la región como colectividad local en Marruecos: análisis institucional de la región de los $\mathbf{9 0}$}

La región es reconocida como colectividad local, es decir, dotada de personalidad jurídica y de autonomía financiera, por la Constitución de 9 de octubre de 1992 y más tarde por la Constitución revisada de 13 de septiembre de 1996.

Quizá el detalle más interesante en cuanto a su reconocimiento constitucional no es sólo el ser considerada como una colectividad local como las prefecturas, las provincias y las comunas (ver figura I), sino que se prevé la representación de las regiones en el seno de la segunda cámara en una proporción de tres quintas partes. El artículo 38 de la Constitución así lo establece: "la cámara de consejeros comprende en una proporción de 3/5los miembros elegidos en cada región por un colegio electoral compuesto por los representantes de las colectividades locales"9.

En el gráfico queda reflejado, a pesar de su sencillez, la complejidad de la administración local en Marruecos. La Administración está vertebrada en dos grandes columnas, una (la de la izquierda) descentralizada, es decir, con unas colectividades locales con cierta capacidad de decisión y de ejecución y, en la otra columna se representa a la administración desconcentrada, es decir, la administración central presente en el territorio a través de unos órganos que dependen directamente de ella. Lo llamativo es que un mismo

9 OuAZZAN ChAHDI, HASSAN (1997), p. 121. Nuestro recorrido por la estructura de la región según se establece en la Constitución de 1996, desde un punto de vista neoinstitucional se basa principalmente en este libro. 
ente, las prefecturas y provincias forman parte de las dos columnas. En el análisis del proceso de descentralización este hecho no sólo hace girar la balanza hacia la administración central, sino que otros factores como la escasez de recursos humanos y financieros y, la escasa cesión de competencias a las colectividades locales hace de la administración descentralizada un débil reflejo de las pretensiones anunciadas en el discurso político oficial marroquí desde los años setenta.

\section{FIGURA I}

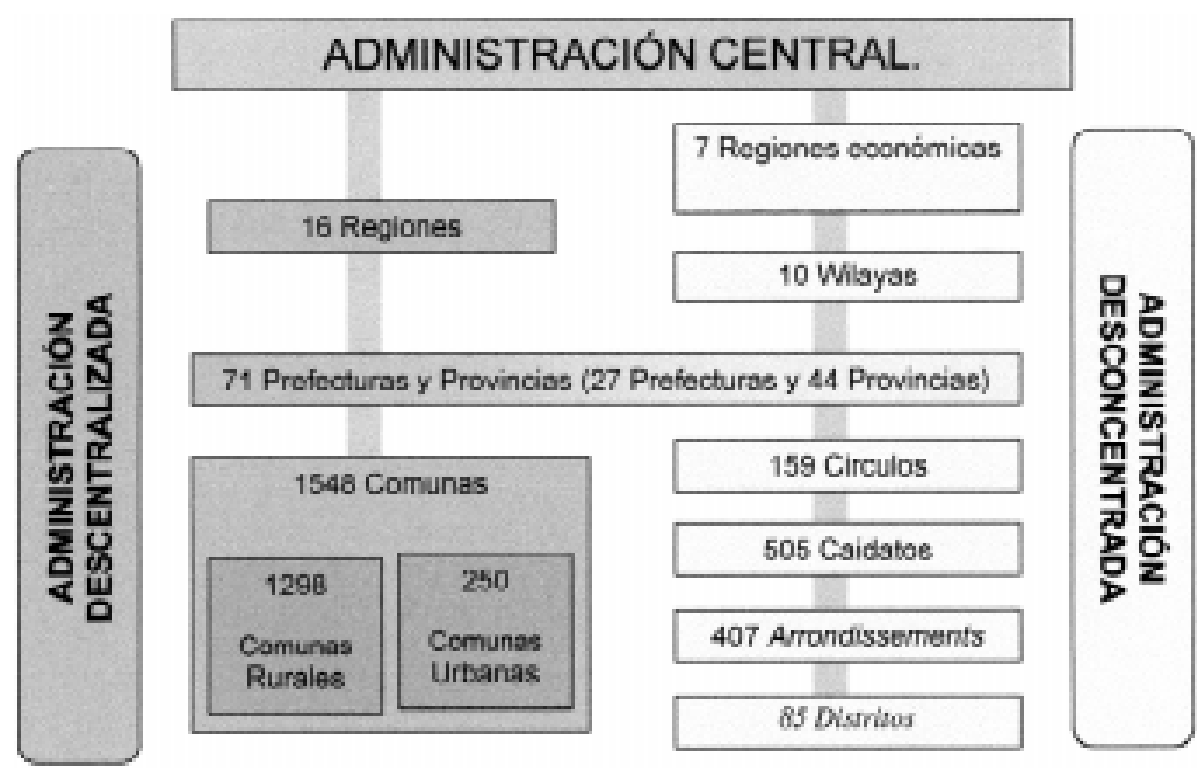

En esta breve introducción podemos señalar también la creación de otro elemento importante: los tribunales de cuentas regionales para garantizar el control de las cuentas y la gestión de las colectividades locales y de sus agrupaciones. El gobernador de la región (que es el gobernador de la provincia que detenta la capitalidad de la región) tendrá un papel preponderante, como ocurre en la provincia y en la prefectura. Las atribuciones del gobernador pueden ser resumidas en: el ejercicio del poder jerárquico; la participación efectiva en la elaboración de las deliberaciones de las autorida- 
des descentralizadas; la ejecución de las decisiones adoptadas por los órganos representativos de las colectividades locales; y la coordinación de los servicios técnicos exteriores implantados en los límites geográficos delas circunscripciones administrativas de las provincias ${ }^{10}$. En cualquier caso el gobernador no es más que un agente desconcentrado que está bajo control, tanto político por parte del Rey, como administrativo por parte de los ministros.

Y en cuanto a las misiones que debe ejercer la región, la ley de 2 de abril de 1997 señala que, dentro del respeto de las atribuciones concedidas a las otras colectividades locales, la región debe contribuir al desarrollo económico, social y cultural de la colectividad regional y, si es necesario, lo hará en colaboración con el Estado y las otras colectividades.

Otro aspecto que queda muy claro en el dahir sobre la construcción regional es que la creación de las regiones no debe de ninguna manera afectar a la unidad de la Nación y a la integridad territorial del Reino. Esto tendrá una clara repercusión en la forma de establecer la división entre las dieciséis regiones ya que se intenta evitar la formación de regiones que guarden similitudes culturales o tradicionales. Es más, si éstas existen de forma natural, la actual división lo que busca es precisamente su destrucción (ver mapa de la división regional, ANEXO I).

No existe una jerarquía entre las distintas colectividades, es decir, que los distintos mecanismos de cooperación previstos entre las regiones y entre las regiones y las otras colectividades locales, nunca puede traducirse en el establecimiento del ejercicio de la tutela de una colectividad sobre otra.

La ley sobre la región establece que "Ios asuntos de la región son gestionados libremente por un consejo democrático elegido por una duración de seis años según la legislación en vigor"11.

El consejo regional está conformado por dos tipos de miembros: los representantes elegidos por las colectividades locales, las cámaras profesionales y los sindicatos y, por otro lado, los miembros del parlamento elegidos en el marco de la región, así como los presidentes de las asambleas prefectorales y provinciales que forman parte de la región, aunque sólo disponen

10 BASRI, DRISS ( 1975), L'Agent d'autorité. Université Mohamed V. Imprimérie Royale, Rabat, p. 63.

11 Artículo 10 del dahir no 1-97-84 del 23 kaada 1417 ( 2 de abril de 1997) sobre la promugalción de la ley no 47-96 relativa a la organización de la región. 
del derecho a asistir a las reuniones del consejo con voz consultiva12.

La elección de los miembros del consejo regional a través de colegios electorales está regulada por el artículo 147 del Código Electoral de 1997. En este artículo se establece que la votación será de lista, de representación proporcional siguiendo la regla del resto más fuerte, sin panachage ni voto preferencial.

Las competencias del consejo regional están determinadas por su composición y por la tutela que se ejerce sobre él y sus actos. De ahí, que éstas se circunscriban a las ya clásicas atribuciones como: la aprobación del presupuesto, la elaboración del plan de desarrollo económico y social y de ordenación del territorio y, el establecimiento de las bases imponibles de sus impuestos. Todas estas decisiones deben ceñirse, claro está, a lo prefijado por el poder central.

Los tímidos avances en materia competencial sólo se dan en cuestiones como la promoción del empleo, la formación profesional, el deporte, medio ambiente y la solidaridad social. Y en cuanto a las atribuciones que el Estado puede transferir sólo está la realización y mantenimiento de hospitales, institutos y establecimientos universitarios, la formación de cuadros, y la inversión en equipamientos de interés regional. Sin olvidar, claro está, las atribuciones que se le concede como experto para emitir sugerencias y opiniones, siempre y cuando no sean sobre cuestiones políticas.

El techo competencial de la región implica una concepción del Estado que por ahora en Marruecos no se está dispuesto a cambiar. No se puede seguir asociando el papel de la región con el desarrollo económico y social de su territorio sin unos medios reales, porque volverá a fracasar la región como colectividad local como ya lo hizo la región económica de $1971^{13}$. Por otra parte, no se puede crear una verdadera descentralización con la atribución de unas competencias colaterales que no van a ayudar al desarrollo de una esfera político-administrativa en el nivel regional.

Y si nos detenemos en los poderes que la carta regional y la Constitución

12 Artículo 3 del dahir de 2 de abril de 1997 sobre la organización regional.

13 La idea era la de crear una confederación de prefecturas y provincias con fines económicos para reestructurar el desarrollo territorial. Formalmente, toda finalidad política estaba excluida. La región era concebida como un nuevo mecanismo para articular una concepción diferente de la teoría del desarrollo, que durante la década de los 60 había mostrado su inoperancia. 
le han otorgado al presidente del consejo regional y al gobernador de la capital de la región, el abismo se hace insuperable y la contradicción se lleva al extremo. En efecto, un presidente y un consejo que deciden, pero que no ejecutan, no son responsables realmente de sus decisiones; y un gobernador que ejecuta las decisiones que no ha tomado tampoco se puede sentir implicado ni responsable de sus actuaciones.

Las competencias del presidente se ciñen a "presidir" las sesiones, a convocarlas, a vigilar el buen desarrollo de estas y a refrendar los actos del gobernador cuando éste ha decidido cómo aplicar las deliberaciones del consejo.

Los poderes del gobernador son, fundamentalmente, la ejecución de las deliberaciones del consejo, poder concluir contratos, elaborar el presupuesto y representar a la región en materia de justicia.

Nada más que el término para hacer referencia a uno y otro ("competencias" para el presidente y "poderes" para el gobernador) nos indica bastante. Recordemos que el presidente tiene cinco días para enviar al gobernador la aprobación de las medidas para la aplicación de las decisiones del consejo. Si el gobernador no recibe en este plazo la contestación del presidente pondrá igualmente en marcha las medidas que estime oportunas para la aplicación de las decisiones.

Por último, el ejercicio de la tutela, tan criticada por su forma de ser ejecutada en la provincia y en la prefectura, se vuelve a reproducir en la carta regional.

Tanto el ejercicio de la tutela sobre los entes descentralizados, como el poder desmesurado del gobernador con respecto a los representantes electos forman parte del grupo de críticas constantes en los Coloquios Nacionales sobre las colectividades locales.

Los mayores inconvenientes que acarrea el ejercicio de la tutela por parte del Ministro del Interior hacia los entes locales son: en primer lugar, el control a priori de todas aquellos actos que pueden tener una mayor repercusión en la vida de la región ${ }^{14}$, con todo lo que de retraso conlleva y

14 Las deliberaciones que necesitan de la aprobación previa para poder ser ejecutadas son las siguientes: el presupuesto general; los préstamos; la apertura de cuentas especiales; la apertura de nuevos créditos y el aumento de los créditos; la aceptación o el rechazo de dones y legados; la fijación de la base imponible, las tarifas y las reglas para la percepción de los 
de desconfianza en la gestión del consejo y también del gobernador. En segundo lugar, el hecho de ejercer la tutela sobre las personas y, especialmente, sobre el presidente y vicepresidente sin delimitar con nitidez las causas de revocación o de suspensión de sus cargos; así como el poder de sustitución (que se trata de la actuación de oficio por parte del gobernador cuando el presidente se niega a realizar una obligación legalmente establecida), hacen tambalear los principios de legalidad y transparencia mínimos en cualquier actuación de los poderes públicos. Estas deficiencias del sistema de tutela son reminiscencias de un viejo sistema de control político que se reviste de administrativo.

\section{Las propuestas realizadas desde 1984 hasta 1996 por el discurso político-teórico y su contrastación en el nivel empírico con la realidad}

Del análisis de los trabajos y documentos aparecidos entre 1984 y 1996 sobre el desarrollo del proyecto de regionalización lanzado por el Monarca en 1984 podemos destacar cuatro puntos coincidentes entre todos ellos, reconociendo de entrada, que las propuestas de su Majestad Hassan II eran excesivas para la realidad social, política y cultural de Marruecos.

Las principales propuestas para un proceso de regionalización acorde con las condiciones del Estado marroquí, se pueden sintetizar en los en los siguientes puntos:

- Evitar los errores de la construcción de la región económica de 1971.

- Profundizar en un proceso paralelo, en la desconcentración, especialmente reformando el estatuto de la provincia y la prefectura ${ }^{15}$.

- El logro de una mayor democratización a través de dos mecanismos: un aumento de las competencias del presidente del consejo regional para que pudiera ejecutar las decisiones del consejo y, mediante el estable-

impuestos, los cánones y los demás derechos en provecho de la región, siempre dentro del marco establecido por la legislación vigente; concesiones, gerencias y otras formas de gestión de los servicios públicos regionales; participación en sociedades de economía mixta; adquisición, alienación, transacciones o intercambios sobre los bienes inmuebles de dominio privado y actos de gestión de dominio público.

15 Ojeda García, Raquel. "La déconcentration au Maroc. Un facteur de modernisation de l'administration et de l'État". En Chanson-J abeurt, Chantal; Prénant, André; Ribeau, Patrick; Semmoud, Bouziane (eds) (2001). Les services publics et leurs dynamiques au Machreq et au Maghreb. L'Harmattan, Paris. 
cimiento del sufragio universal directo para la elección de los consejeros regionales.

- La división administrativa no tiene que responder a criterios culturales o a viejas identidades y, en ningún caso, podrá cuestionar la integridad y la unidad de la Nación.

De todas estas propuestas sólo la última es la que se ha realizado, las anteriores no. Las justificaciones que se han dado al respecto, una vez descubierto el salto entre lo sugerido como conveniente y lo que la política ha hecho bajo el beneplácito de todas las fuerzas políticas insertas en el juego institucional parlamentario, se centran principalmente en los siguientes aspectos: el carácter transitorio del estatuto de la actual región, es decir, no se cierra a futuras evoluciones; la débil situación económica y financiera y por último la inmadurez del pueblo y también de sus elites.

Si volvemos con un poco de más detenimiento a las cuatro condiciones para el proceso de regionalización establecidos por los teóricos, podemos afirmar que:

5.1. La primera condición se cifraba en la superación de los errores de la región económica de 1971. Según Brahimi algunos de los principales errores de la construcción regional de 1971 fueron la apertura inoportuna de largos pasillos artificiales para que todas las regiones tuvieran una salida al mar ${ }^{16}$; y la unión a veces "heterogénea" de territorios entre los cuales no existía ninguna complementariedad ${ }^{17}$.

La región económica de 1971 no contaba con los medios de intervención administrativa necesarios, ni con los recursos técnicos y financieros para alcanzar los objetivos que, de forma muy generosa, se habían propuesto sus promotores.

Según el documento elaborado por el Conseil National de la Jeunesse et I'Avenir sobre Région, régionalisation et emploi hay tres factores principales que resumen las causas del fracaso de la región económica:

16 Al menos consiguieron que seis de las siete regiones económicas contaran con un puerto marítimo importante.

17 Brahimı, Mohamed (1996), "La régionalisation: quelle faisabilité?". En Revue Marocaine d'Administration locale et de développement. Série Thèmes actuels, no 8, pp. 11-27, p. 15 
- Para los promotores de la región de 1971, el desarrollo regional era concebido como una simple regionalización del plan trazado por los poderes centrales. Su puesta en marcha tampoco tenía en cuenta una aproximación de conjunto del sistema económico, social y espacial de la región ${ }^{18}$.

- Tampoco quisieron crear ni establecer una institución, un centro autónomo que ejerciera responsabilidades públicas. Al no poder contar con los mecanismos institucionales ni los recursos económicos, las regiones económicas se convirtieron en un foro para expresar las quejas de las provincias.

- Por otro lado, la desconcentración que se hizo a favor de las regiones fue muy limitada lo que le impedía ser una institución efectiva, mientras que las comunas conocían una importante reforma en 1976 en donde se avanzaba hacia la descentralización ${ }^{19}$.

\subsection{La importancia del proceso de desconcentración}

El mantenimiento del estatuto de la provincia y de la prefectura ${ }^{20}$ lo único que puede provocar es una descentralización a dos velocidades. El papel central que ocupa el gobernador en la vida provincial deja poco espacio para el desarrollo y la intervención de los otros actores territoriales. La cohabitación y la colaboración entre la región y la provincia no se pueden concebir a menos que las dos tengan las mismas fuentes de legitimidad (democrática) y que funcionen según un esquema piramidal coherente ${ }^{21}$.

La reforma de las administraciones centrales, el cambio que debe sufrir su

18 Para Abdelhadi Raounak (1996) la región de 1971 constituye más un objeto de planificación que una autoridad que participe a través de la concertación en los procesos de elaboración de los planes de desarrollo económico y social. "Quel renouveau régional au Maroc?". En Revue marocaine d'administration locale et de développement., $\mathrm{n}$ - 8, p. 74.

19 Royaume du Maroc. Conseil National de la Jeunesse et l'Avenir (1996).

20 En la figura I queda muy claro como la colectividad local, la provincia y la prefectura forman parte tanto de la adminstración desconcentrada como de la descentralizada.

21 Brahımı llega a hablar de hipoteca prefectoral y provincial, y que si no se avanza en la desconcentración el camino que le queda a la región, será un camino de cruces. Art. Cit., p. 23. 
mentalidad para que pierdan el miedo a la desconcentración, será la mejor compañía para la descentralización ${ }^{22}$.

\subsection{La garantía de una mayor democratización}

El papel del presidente será clave para dar una mayor credibilidad a la región. Si éste goza de los recursos necesarios y de unos amplios poderes se podrá avanzar en el proceso de la descentralización pero con mecanismos más democráticos. El poder ejecutivo debe ser devuelto a los órganos propios de la región, es decir, al presidente del consejo regional y no a la autoridad regional que representa al poder central, el cual debería encargarse exclusivamente del control de legalidad de las decisiones adoptadas por el consejo $0^{23}$, nos referimos al gobernador de la región.

La forma de elección para la conformación del consejo regional debería ser el sufragio universal directo para la representación de los intereses políticos y el sufragio indirecto para la representación de los intereses económicos y sociales. Además si la descentralización consiste en asegurar una mayor participación de la población en el desarrollo de su país habría que dar cabida a una mayor representación de todas las capas de la población y no sólo a algunos representantes de los partidos políticos y de la administración ${ }^{24}$.

\subsection{Los criterios de la división regional}

La delimitación territorial para la construcción de las nuevas regiones en función de una identidad construida sobre un espacio geográfico, una historia y unas claves culturales comunes es muy difícil realizar en Marruecos que, como ha señalado Brahimi, la misma historia ha hecho que sea prácticamente imposible identificar esas fronteras naturales. Es más, para este autor es excesivo creer que la conciencia nacional sea hija de la

22 Esta misma idea la podemos encontrar en el documento del CNJ A. Régions, régionalisation et emploi. Y en el artículo de M'hamed Zrioul (1996), "La nouvelle région économique au Maroc: dynamismes et enjeux" en Revue marocaine d'administration locale et de développement, no. 8, pp. 54 y 57.

23 Raounak, Abdelhadi. Art. Cit., p. 83.

24 El Yaagoubi, Mohamed (1996), "La région telle qu'elle pourrait être au Maroc" En Revue marocaine d'administration locale et de développement, $n=8, p .93$. 
naturaleza, sino que también puede nacer por decreto ${ }^{25}$, y toma como ejemplo el proceso de regionalización en Francia.

La región en Marruecos procede de una idea de racionalización más que de los lazos afectivos con el territorio. No es el fruto de un combate regionalista, sino de una voluntad consciente desde el poder central de conceder a los territorios los medios institucionales para su desarrollo. "La región es concebida por tanto, como una simple circunscripción de gestión".

Ya habíamos dicho en la introducción de este apartado que los tres primeros aspectos han sido los que no se han alcanzado, mientras que el respeto a la hora de trazar la división regional de los criterios más arriba establecidos ha sido la única consecución de las cuatro proposiciones comunes para la construcción institucional de la región como colectividad local.

En cuanto a las justificaciones que se han adelantado para explicar el desnivel producido entre las propuestas (que se trata de un proceso no terminado, la escasez de recursos financieros y la inmadurez de las elites) y los hechos podemos detenernos en primer lugar en el tema de la democratización. Brahimi afirma que para evitar el brusco paso a la elección por las urnas de los representantes de los ciudadanos en el consejo, que podría acarrear ciertos riesgos, es preferible la elección indirecta, es decir, avanzar con reformas "mesuradas para prevenir contra los excesos y preparar con tranquilidad las evoluciones" 26 .

Además, la región ha llegado en un mal momento: los presupuestos estatales están sometidos a unas restricciones importantes bajo los mandatos del Fondo Monetario Internacional y el Banco Mundial para conseguir reducir la deuda externa y la inflación. Las dificultades en las que se encuentra la economía minan la elasticidad del recurso al sistema fiscal y desaparece el ahorro de los circuitos. Por otro lado, la presión social dificulta los ya estrechos márgenes de maniobra de los poderes públicos, y las colectividades locales se ven llamadas a la impotencia.

Entre los poderes públicos persiste la desconfianza hacia la "inmadurez" de la población que es considerada como un menor de edad. Por tanto dejar en sus manos, primero, la elección directa de sus representantes y, sobre

25 Brahimı, M. "La régionalisation: quelle faisabilité?". Art. Cit., p. 17.

26 Brahimı, M. Art. Cit., p. 19. 
todo, la gestión de los asuntos locales sería un acto de irresponsabilidad.

Brahimi se pregunta una vez planteadas todas estas dificultades si acaso esta descentralización en el nivel de la región no ha sido una "descentralización de más"27.

\section{A modo de conclusión}

En este artículo sobre el amplio y complejo proceso de regionalización nos hemos centrado sólo en tres aspectos que son a nuestro entender reveladores de la situación actual no sólo de la descentralización alcanzada en el 2002 sino del estado del sistema político-administrativo de Marruecos.

Los tres aspectos han sido: la valoración y el análisis de los efectos del discurso del Monarca en Fez en 1984, el análisis institucional de la región reconocida en la Constitución de 1996 como colectividad local y su posterior desarrollo legislativo a través de la carta regional de 2 de abril de 1997 y por último, nos hemos centrado en las proposiciones establecidas por el discurso de Hassan II en 1984 no alcanzadas, y en las adaptaciones posteriores de estas propuestas realizadas por expertos y teóricos para ajustarlas a las exigencias políticas, sociales y culturales del país, que tampoco han sido llevadas a la práctica. Ni la regulación legislativa ni su implementación han cubierto las expectativas creadas por el inicio del proceso de regionalización en 1984.

Quedan muchas preguntas sin contestar, lo que sí podemos atrevernos a decir es que la región según y como está reconocida normativamente en la actualidad, no es un ente descentralizado por cuatro razones que ya hemos justificado y que se vienen denunciando desde hace tiempo para el caso de la provincia y de la prefectura: la elección indirecta de sus representantes, la escasez de competencias que se le han atribuido al consejo regional, el fuerte papel del gobernador, y el ejercicio de la tutela a priori por parte del Ministro del Interior.

Por tanto, si la construcción regional no ha venido motivada por ninguna demanda social, identitaria o política, si realmente no representa los intereses de una población, si no se ha dejado decidir a las distintas provincias y comunas a qué región querían pertenecer, sino que ha sido decidido por

27 Brahimi, M. Art. Cit., p. 27. 
decreto, si ni siquiera se reconoce la capacidad de los representantes de la población para la mera gestión económica, si además se ha creado en un mal momento económico con lo que ha supuesto una multiplicación de los gastos con unos escasos recursos que debe disputarse con las otras colectividades locales, la única respuesta que cabe para explicar el impulso de la regionalización a mediados de la década de los 90 , cuando la meta de salida fue propuesta en 1984 con el discurso de Fez, es exclusivamente política. Sólo por razones políticas se ha llegado hasta este punto y su contexto es el consenso y las grandes reformas institucionales que se están viviendo en el país.

El grave inconveniente es que la corta perspectiva histórica no nos permite ver quienes son por ahora los ganadores y quienes los perdedores de esta apuesta política por la región en Marruecos.

\section{Bibliografía}

La région. Une nouvelle collectivité locale. Publication de la Revue Marocaine d'Administration locale et de développement. Série Textes et documents. 1997, p. 65.

"Les principaux éléments du contrat de la gestion déléguée à Rabat-Salé". En Revue Marocaine d'Administration locale et de développement, pp. 239-241. № 23. Avril-juin, 1998.

Région, régionalisation et développement régional. Publications de la Revue Marocaine d'Administration locale et de développement. Série Thèmes actuels, no 8, 1996.

Abouhani, Abdelghani (1994), "Les pouvoirs dans la ville: multiplicité des centres de decision et attitude des populations". En Correspondances, no 14. J anvier, pp. 9-14.

AntaRI, M'HAmed (1997), "La participation du juge administratif à la tutelle sur les actes du conseil régional". En Revue Marocaine d'Administration locale et de développement, no 19, avril-juin, pp. 83-90.

BASRI, DrISS (1990) , L'administration territoriale. L'expérience marocaine. Paris, Bordas.

Blanc, J acques; Rémond, Bruno (1994), Les collectivités locales. Paris, Presses de Science Po \& Dalloz. 
Brahimi, Mohamed (1997), "Appréciation de la régionalisation à l'ombre de la recomposition politique et institutionnelle". En Revue Marocaine d'Administration locale et de développement, no 19, avril-juin, pp. 35-82.

- (1998), "De l'efficacité des contrôles exercés sur les collectivités locales". En Revue Marocain d'Administration locale et de développement, $\mathrm{n}-23$, avril-juin, pp. 35-64.

Claisse, Alain (1998), "Quelle décentralisation pour quel développement au Maroc et en France?". En Revue Marocain d'Administration locale et de développement, no 22, janvier-mars, pp. 11-14.

- (1998), "Représentation, gestion, développement: les trois dondements de la décentralisation". En Revue Marocaine d'Administration locale et de développement, $\mathrm{n}$-22, janvier-mars, pp. 15-24.

El Mhamdi, Ali (1984), "Le concept de la concertation dans l'Administration publique: essai d'analyse théorique". En Revue juridique politique et economique du Maroc, № 16, décembre, pp. 89-111.

El YaAgoubi, Mohamed (1997), "La gestion déléguée des services publics locaux au Maroc". En Revue Marocaine d'Administration locale et de développement, no 19, avril-juin, pp. 143-161.

- (1998), "L'idée de transparence dans la loi relative à l'organisation de la région au Maroc". Revue Marocaine d'Administration locale et de développement, no 22, janvier-mars, pp. 25-38.

Gruber, Annie (1996), La décentralisation et les institutions administratives, Paris, Armand Colin, 2ème edition.

Khatabi, Mustapha (1998), "Rôle de l'université en matière de formation et de conseil des élus locaux". En Revue Marocain d'Administration locale et de développement, no 23, avril-juin, pp. 65-70.

Mouddani, Omar (1982), “Reflexions sur les donnees et les limites du processus de la reforme des administrations de l'état au Maroc", en Intégration, nำ18, décembre, pp. 24-36.

OuAZZANI CHAHDI, HASSAN (1997), Droit administratif. L'organisation administrative, Casablanca, Fondation Konrad Anenauer.

Rousset, Michel (1992), “Quel renouveau régional?”, en al Asas, no 113, pp.6-14.

- (1985), "La nouvelle étape de la regionalisation au Maroc: le passé ne 
répond pas del'avenir", en Revue française d'administration publique, $n \cong 35$, juillet-septembre, pp. 477-489.

Rousset, Michel; Basri, Driss; Belha, Ahmed; Garagnon, J ean (1992), Droit administratif marocain. Collection Edification d'un état moderne. Rabat, Imprimérie Royale, 5ème édition.

Royaume du Maroc. Conseil National de la Jeunesse et l'Avenir (1996), Région, régionalisation et emploi. Laâyoune, Cinquième session, 15, 16.

- (1998), L'administration de demain et les attentes des jeunes, Septième Session, 21 et 22 de mai, Rabat, Okad.

Sedjarl, Alı. (dir) (1996), État-nation et prospective des territoires, Rabat, L'Harmattan y GRET.

Smires, M'faddel, "Le juge administratif et la décentralisation". En Revue Marocaine d'Administration locale et de développement. Série Thèmes Actuels. 1957-1997. 40 ans de justice administrative au Maroc, no 14, pp. 59-80.

ZRioul, M'HAmed (1990), La région économique au Maroc. Quel avenir?, Rabat, Okad.

- (1996), Edification de la région économique au Maroc, Rabat, Okad. 
ANEXO I

\section{REGIONES ADMINISTRATIVAS}

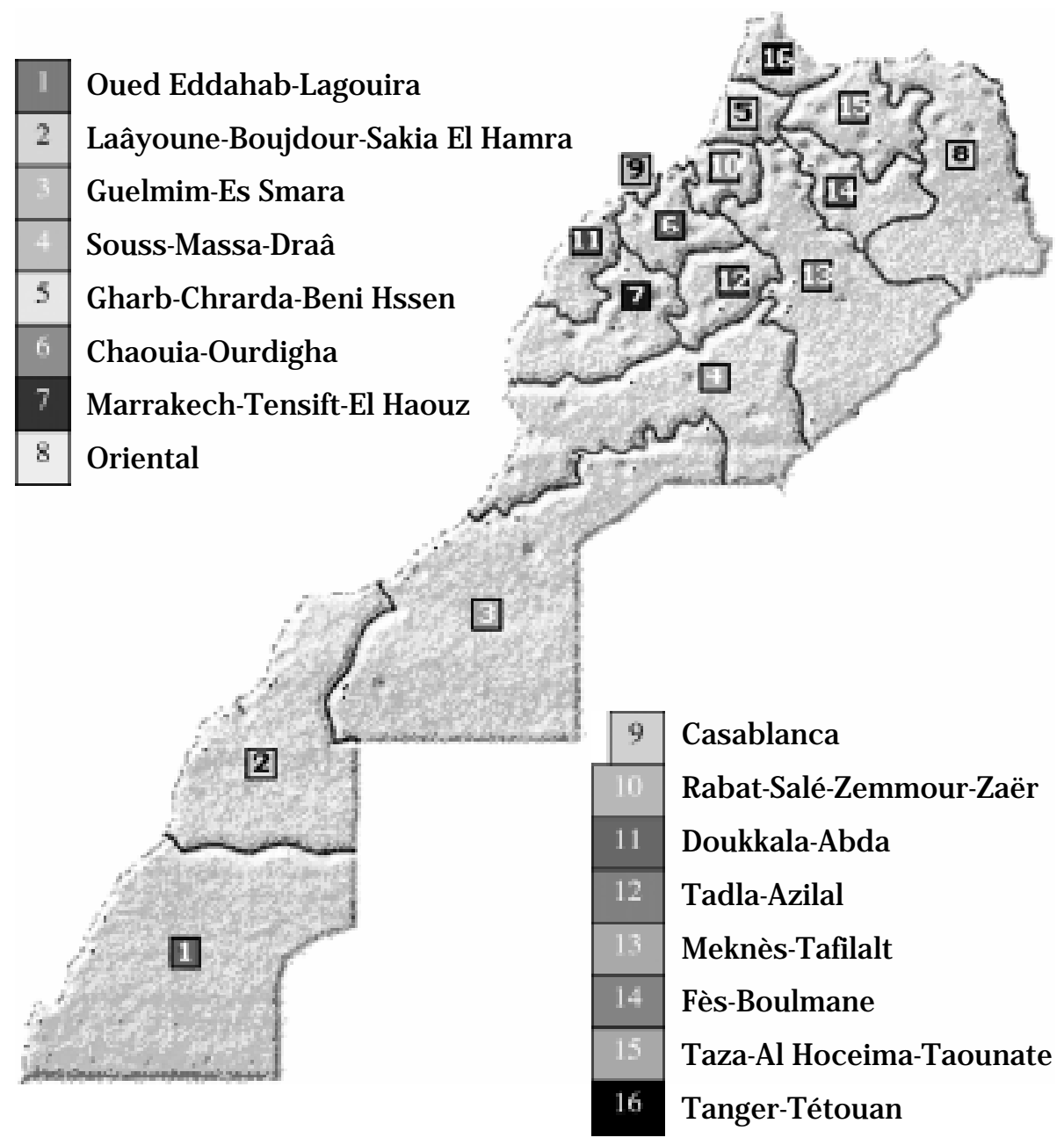

